\title{
Global failures
}

Overcoming human poverty will require a quantum leap in scale and ambition... The Millennium Development Goals are still technically feasible in even the poorest countries, but the window of opportunity is rapidly narrowing and the political will remains largely absent. — Kofi Annan, $2004^{1}$

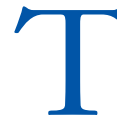

his year's report on progress toward the United Nations' eight Millennium Development Goals ${ }^{1}$ must have been difficult to write: 26 pages of failures and faltering progress. Usually careful but optimistic in his public comments, UN Secretary-General Kofi Annan is decidedly sombre this time around.

The Millennium Development Goals range from eradication of extreme (not merely debilitating) poverty and hunger, to universal primary (not secondary) education, to reducing (not eliminating) the morbidity and mortality gaps between rich and poor, along with achieving gender equity and environmental sustainability. But, despite the fact that these goals are modest and realizable, progress has been limited or nonexistent for most regions and targets.

In sub-Saharan Africa, Latin America and the Caribbean there has been little or no progress in eradicating extreme poverty and hunger; in Western Asia, they have increased. In sub-Saharan Africa and southern Asia respectively, 31\% and $47 \%$ of children under age 5 are underweight, and under-five mortality is over 20 and 10 times higher respectively than in developed countries. HIV infections rose to an estimated 38 million in 2003; in Southern Africa, $24 \%-39 \%$ of pregnant women in urban capitals are infected. And so on across most of the 48 indicators of progress toward the Millennium Goals.

The Secretary-General is at his darkest when reporting on the devastating effects of ongoing armed conflicts around the globe, which in the past decade have resulted in over 5 million deaths. Although the conflict in Iraq has dominated media coverage since the UN heard the American case for military intervention in September 2002 and has cost an estimated 13000 to 15000 (mostly civilian) lives (www.iraqbodycount.net), most of the losses to war are occurring in conflicts that are barely mentioned in the news. ${ }^{2}$

Armed conflict and political strife are costly in many ways; they cripple economies and divert funds for armaments and policing that could otherwise be directed to the Millennium Goals. Societal dysfunction is also associated with the growing phenomenon of transnational crime focused on trafficking in "whatever is available for profit from nuclear waste and firearms to protected species, cultural artefacts and, most tragically, human beings."1
There are many and persistent reasons for the collective failure to clear the Millennium hurdles. One of these is inadequate funding for aid and research. The UN's beg-andchide strategy has not worked: only 5 countries are in the club that delivers $0.7 \%$ of their GDP to development assistance. Canada is not among them.

In this issue (see page 1203) Prabhat Jha and colleagues summarize the main global health problems and review the evidence that the international burden of ill health can be corrected with a comparatively small investment in disease treatment and prevention. ${ }^{3}$ To an important degree, new technologies will be an enabling force. Genomics and molecular medicine are providing improved vaccines and new antimicrobials for existing and emerging infectious agents; modern health education and health services delivery techniques have improved rates of condom use and the deployment of insecticide-coated mosquito nets. Such advances do reduce death rates and improve health and life expectancy and will be needed to confront emerging pathogens.

Gains in life expectancy not only improve health but are a direct economic stimulus. This compounding return on investment means that even a modest program to control major diseases can result in huge economic gains. For example, it is estimated that the world economy saved \$27 billion over the 20 years after the eradication of smallpox (which cost but $\$ 300$ million). In Thailand, the rate of return for HIV prevention is between $12 \%$ and $32 \%$ annually. ${ }^{3}$ Such strategies are being discussed this week in Toronto at an international conference sponsored by the Canadian Centre for Global Health Research (www.cghr.org).

Mr. Annan frames his report in sober reminders that the Millennium Goals cannot be accomplished without international respect for the rule of law - a requirement equal in importance to " $[\mathrm{k}]$ nowledge, capacity and the political will to act." Without peaceful conflict resolution, efficacious health programs cannot be deployed and the investment confidence of donor countries, along with their aid, with continue to be stalled. - CMAf

\section{References}

1. United Nations General Assembly. Implementation of the United Nations Millennium Declaration. Report of the Secretary-General. 2004 Aug 27. Doc. no. A/59/282. Available: www.un.org/millenniumgoals/ (accessed 2004 Oct 17).

2. Médecins sans Frontières. The top ten most underreported humanitarian stories of 2003. Available: www.msf.org/content/page.cfm?articleid=AA4451CE6C9E-4516-A063A1D44C3205CA (accessed 2004 Oct 17).

3. Global IDEA Scientific Advisory Committee. Health and economic benefits of an accelerated program of research to combat global infectious diseases. CMA7 2004;171(10):1203-8. 